\title{
Food Conditioning Affects Expression of Insect Resistance in Diploid Willows (Salix spp.)
}

\author{
Christer Björkman $^{1 *}$, Karin Eklund ${ }^{1}$, Anna Lehrman ${ }^{2}$, Johan A. Stenberg ${ }^{1}$ \\ Department of Ecology, Swedish University of Agricultural Sciences, Uppsala, Sweden; ${ }^{2}$ Department of Crop Production Ecology, \\ Swedish University of Agricultural Sciences, Uppsala, Sweden. \\ Email: ${ }^{*}$ christer.bjorkman@slu.se
}

Received October $3^{\text {rd }}$, 2012; revised November $7^{\text {th }}$, 2012; accepted December $7^{\text {th }}$, 2012

\begin{abstract}
The high energy quota and versatility of use make willows (Salix spp.) attractive as bioenergy crops. Insect defoliation constitutes a threat to the profitability of willow growers. Hitherto, the breeding for resistance against the main insect pests has been hampered by the fact that all known resistant willow clones are polyploids, and existing molecular breeding tools work most effectively for diploids. Here, we firstly report diploid willows highly resistant to the main insect defoliator, the leaf beetle (Phratora vulgatissima), offering new opportunities for breeding resistance. Leaf beetles exposed to three resistant clones (two S. purpurea one S. eriocephala) laid three to 27 times fewer eggs than females on a susceptible $S$. viminalis clone. Secondly, we show that beetles laid significantly more eggs on resistant clones if they were fed the susceptible clone prior to the oviposition monitoring test compared to when they pre-fed on resistant clones. Nevertheless, the differences observed between resistant and susceptible clones were pronounced in all cases. The food conditioning effect means that small differences in resistance among clones may be undetected.
\end{abstract}

Keywords: Short-Rotation Coppice; Willow; Bioenergy Crop; Insect Resistance; Conditioning

\section{Introduction}

The demand for renewable sources of energy is continuing to increase. Biofuels, i.e., liquid, gas or solid fuels produced from biomass, are already responsible for a significant part of the renewable energy currently produced and are expected to become even more important in the near future [1]. Willows (Salix spp.) could potentially be an important bioenergy crop for producing biofuels. At present, willows are grown in Sweden, the UK and several other countries in Europe as a short-rotation coppice crop [2]. Growing willows provides farmers with an alternative and potentially profitable use of land that may otherwise be poorly suited for traditional agricultural crops. The fast growth of willows allows harvesting every 2nd to 5th year, depending on growth conditions. Burning is the most common use of willows, but transformation into ethanol and bio-diesel is also possible. Willows are well-suited for all these purposes due to their high energy quota and efficient use of nitrogen; high yields are possible even with a relatively low input of fertilization [3]. In addition, willows are increasingly used for cleaning waste water and soil remediation $[4,5]$.

Insect defoliation constitutes an imminent threat to the profitability of willow growers. In Sweden as in other

${ }^{*}$ Corresponding author. parts of northern Europe, the main insect pests are different species of leaf beetles (Colepotera: Chrysomelidae). In particular, the blue willow beetle (Phratora vulgatissima L.) has caused extensive damage [6]. Heavy defoliation by adult beetles and larvae is reported to reduce plant biomass production by $40 \%$ [7]. High leaf beetle densities occur frequently in willow plantations [8]. The use of insecticides is not feasible due to economic and environmental issues. It is therefore important to identify practical, economic and environmentally acceptable control strategies for these beetles. The breeding for resistance will almost certainly form part of such a strategy. Adapted harvesting regimes are another part in controlling the beetles $[8,9]$ that may also affect productivity [10].

Hitherto, the breeding for resistance against leaf beetles in willows has been hindered partly because all known resistant genotypes have been shown to be polyploids [11,12] and partly because a lack of efficient and reliable resistance protocol. Concerning the first hinder, existing molecular tools are most effective for diploids as the analysis of plants with several chromosomes requires a considerable amount of time and effort due to the multitude of ways in which markers may segregate. Thus, even though it has been possible to create crossing populations with a wide variation in phenotypic expression of 
leaf beetle resistance, it has been difficult to identify genetic markers, such as QTLs, targeting genes coding for resistance $[13,14]$. This means that only traditional, and hence time consuming, methods of breeding have been possible. Concerning the second hinder, we have recently developed a protocol for quantifying insect resistance against the main insect pest $P$. vulgatissima that is both time effective and reliable [12]. However, there have been indications that the food $P$. vulgatissima beetles experience before they are tested on a clone may affect the results of the bioassay. In this paper we quantify the effect of the herbivore's experience of other plant clones prior to the experimental test on the possible detection of resistant willow genotypes and the expression of resistance. We also present the first data showing that genotypes of the diploid willow species $S$. purpurea and $S$. eriocephala are strongly resistant to the leaf beetle $P$. vulgatissima.

\section{Materials and Methods}

The direct insect resistance of three diploid willow clones, i.e., FC (or "Fish Creek" a S. purpurea L. clone with ID 9882-34 (male)), OO6 (another S. purpurea clone with ID 94006 (female)) and S25 (a S. eriocephala Michx. Clone (female)), was estimated by comparing them to the well-studied susceptible diploid $S$. viminalis L. clone 78021 (female). It is worth noting that there are other susceptible diploid S. viminalis clones that are males (e.g. Jorr). Thus, there are opportunities to create crossing populations. The bioassay method used was recently developed and has been shown to be a timeefficient method for reliably scoring direct resistance (see [12] for a detailed description) that corresponds to observed variation in defoliation in the field among a subset of clones (Inger Åhman unpublished data). Adult female $P$. vulgatissima leaf beetles were allowed to lay eggs on detached willow leaves from the different clones. The experiment was conducted over 14 days. Leaf-beetle egg production stabilized over time, and the number of eggs laid (averaged per day) during the last census period (day 13 - 14) was used as an estimate of the degree of willow resistance. The experiment was repeated in two years (2010 and 2011). In 2011, females were allowed to feed either on the susceptible clone 78021 or on the respective resistant clone prior to the oviposition monitoring test but the number of replicates in each pre-treatment clone were not high enough to allow a proper statistical analysis. Thus, these data were pooled and pre-clone was denoted "mix". In 2010, we also quantified the effect of the food female beetles were offered prior to the oviposition test ("pre-clone"). Thus, some females were pre-fed with leaves from the same willow clone as their egg production rates were later tested on, while others were pre-fed with leaves from the 78021 clone.

Data was analyzed using SAS 9.2. In the diploid willow experiment, GLM ANOVA analyses were used, following log-transformation of the data set to ensure normal distribution. In both 2010 and 2011, differences in egg production between the clones (78021, FC, OO6 and S25) were tested by one-way GLM ANOVAs after all female leaf beetles had been allowed to feed on the willow clone 78021 prior to the oviposition monitoring test. In 2010, the effects of which clones the females fed on during ("test-clone") and before ("pre-clone") the oviposition test, as well as the interaction between these two factors, were tested in a two-way ANOVA (proc GLM). The latter analysis only included the clones FC, OO6 and S25. In addition, the oviposition rate per day during the last census period (day 13 - 14) on the susceptible clone 78021 was used to test for differences between years. The number of replicates in the above described experiments varied between 6 and 20, which should be enough to achieve a reliable estimate.

\section{Results}

The oviposition rate differed between the "test-clones" in both 2010 and 2011 (Figure 1; 2010: $F_{3.70}=12.0, P<$ 0.001; 2011: $\left.F_{3,33}=23.3, P<0.001\right)$ after the female beetles had fed on the susceptible clone 78021 prior to the oviposition monitoring test; i.e. only the data with 78021 as pre-clone in 2010 and a subset of the data in 2011. In both years, the oviposition rate on clone 78021 was 3 - 27 times higher than the oviposition rates on the other diploid clones, irrespective of pre-clone. The specific pre-clone that the females fed on before the oviposition test influenced the oviposition rates but could only be properly analysed in 2010 (Figure 1; $F_{1.91}=18.2, P<$ 0.001). Females that prior to the oviposition monitoring test were allowed to feed on 78021 laid on average 139\% more eggs compared to females that had pre-fed on their respective test-clone (Figure 1; 2010 data). Female leaf beetles tested on the diploid clones FC, OO6 and S25 showed a similar response regardless of which clone they had been feeding on prior to the oviposition monitoring test (78021 or their own test-clone) as illustrated by the non-significant interaction between pre-clone and testclone $\left(F_{2.91}=0.66, P=0.521\right)$. In addition, there was no significant difference in oviposition rate between years on clone $78021\left(\mathrm{~F}_{1.30}=1.91, P=0.177\right)$.

\section{Discussion}

The results presented here are to the best of our knowledge the first to clearly demonstrate the existence of diploid willows resistant to the leaf beetle Phratora vulgatissima. This discovery opens up new opportunities for breeding resistance in this bioenergy crop. The fact that 


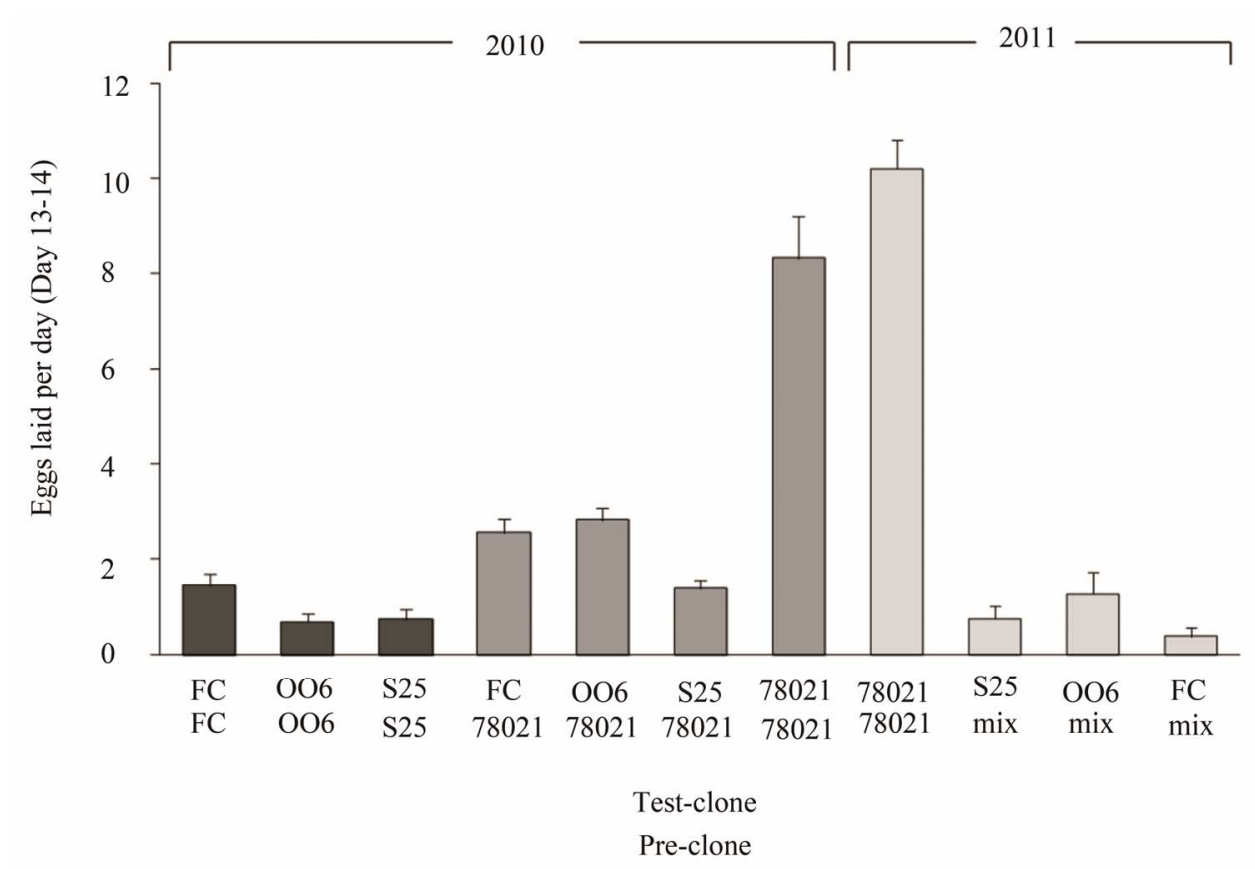

Figure 1. Oviposition rate by willow leaf beetles on diploid willow test-clones. Mean (+SE) number of eggs laid per day during day 13 and 14 after transfer to experimental willow (Salix spp.) clones gives a good measure of direct resistance against the leaf beetle Phratora vulgatissima. Female beetles were allowed to feed on different willow clones prior to the start of the experiment (pre-clones). FC = the $S$. purpurea clone "Fish Creek" (ID 9882-34); $006=$ a $S$. purpurea clone officially entitled ID 9882-34; S25 = a $S$. eriocephalia clone; 78021 = the $S$. viminalis clone 78021; and "mix" = females had been feeding on either susceptible or resistant clones and results were pooled due to low n-values. Data from two years (2010 and 2011$)$ are presented. $\mathbf{N}=\mathbf{6}$ - 20.

we now know that there are both susceptible and resistant Salix clones, of both sexes, that are diploid give opportunity to make crossing populations in which genetical markers for resistance may be more easily sought. A complicating factor in the search for resistance is the observed influence on the estimate of direct resistance of food type beetles experienced before the actual bioassay.

The difference between egg production on resistant (clones FC and OO6 of S. purpurea and clone S25 of $S$. eriocephala) and susceptible (clone 78021 of $S$. viminalis) willows was highly significant and varied between 3 times (300\%) and 27 times (2700\%). Given that adult females can lay up to 600 eggs [12], it can be estimated that it would take 213 to 1609 days to realize the fecunddity on the resistant clones compared with 59 to 72 days on the susceptible 78021 clone. While we do not know the average longevity of an adult female in the field, we know that they can survive for over 100 days in the lab [12]. Thus, female $P$. vulgatissima feeding on the resistant willows are unlikely to realize more than a small fraction of their egg-laying capacity under natural conditions. As the larvae normally cause most of the damage, the positive effect on willow growth by using resistant willows in the field is likely to be substantial.

The level of resistance varied between years. To some extent, this variation can be attributed to the type of food the female beetles experienced prior to the oviposition test, i.e., the pre-clone [15-17]. Based on the data from 2010, beetles laying eggs on the resistant clones (FC, OO6 and S25) after feeding on the susceptible clone (78021) as pre-clone produced on average 1.4 times more eggs than those allowed to feed on their respective clones as pre-clones. This highlights the importance of considering the type of food leaf beetles are allowed to feed upon before monitoring oviposition. In this particular case, the differences between resistant clones and susceptible clone were significant irrespective of the preclone (Figure 1).

The mechanisms behind the variation in plant quality were not studied, but it is well known that phenolic compounds, particularly salicylates, contribute to insect resistance in willows and that the expression of these compounds depends on ontogeny, light conditions, habitat etc. [6,11,13,18-20].

In the present study, we only measured direct resistance to the leaf beetles. Further work is needed to show whether indirect resistance, acting via natural enemies, show similarities to previous results, i.e., a positive link, and thus no trade-off between direct and indirect resistance [21-23]. Sustainable control via plant resistance is likely to require effective use of both direct and indirect effects on the target pest. 


\section{Conclusion}

In conclusion, our discovery of diploid willow clones exhibiting a high degree of resistance to the leaf beetle $P$. vulgatissima opens up new possibilities for targeting genes and assists the search for genetic markers of resistance in willow species. A logical next step would be to create a crossing population between one of these resistant diploid clones and a susceptible diploid clone of the species $S$. viminalis. Such a crossing population could be very useful in screening for genetic markers such as QTLs, and furthermore, offers opportunities for the identification of the genes associated with both direct, i.e. plant chemistry, and indirect, i.e., interactions between herbivores and their natural enemies, resistance traits.

\section{Acknowledgements}

We are grateful to Lawrence B. Smart for recommending clones and supplying us with cuttings of the resistant clones. We thank Hans Johansson for help with insect bioassays and plant nursing. Ann-Christin Rönnberg Wästljung gave valuable comments on the manuscript. The work was funded by the Swedish Energy Agency, the Faculty of Natural Resources and Agricultural Sciences at SLU and Lantmännen Agroenergi AB.

\section{REFERENCES}

[1] D. P. Van Vuuren, E. Stehfest, M. G. J. den Elzen, T. Kram, J. van Vliet, S. Deetman, M. Isaac, K. K. Goldewijk, A. Hof, A. Mendoza Beltran, R. Oostenrijk and B. van Ruijven, "RCP2.6: Exploring the Possibility to Keep Global Mean Temperature Increase below $2^{\circ} \mathrm{C}$," Climatic Change, Vol. 109, No. 1-2, 2011, pp. 95-116. doi:10.1007/s10584-011-0152-3

[2] I. Dimitriou, H. Rosenqvist and G. Berndes, "Slow Expansion and Low Yields of Willow Short Rotation Coppice in Sweden; Implications for Future Strategies,” Biomass \& Bioenergy, Vol. 35, No. 11, 2011, pp. 4613-4618. doi:10.1016/j.biombioe.2011.09.006

[3] A. Karp and I. Shield, "Bioenergy from Plants and the Sustainable Yield Challenge,” New Phytologist, Vol. 179, No. 1, 2008, pp. 15-32. doi:10.1111/j.1469-8137.2008.02432.x

[4] P. Aronsson, T. Dahlin and I. Dimitriou, "Treatment of Landfill Leachate by Irrigation of Willow Coppice-Plant Response and Treatment Efficiency,” Environmental Pollution, Vol. 158, No. 3, 2010, pp. 795-804. doi:10.1016/j.envpol.2009.10.003

[5] M. Mleczek, P. Rutkowski, I. Rissmann, Z. Kaczmarek, P. Golinski, K. Szentner and A. Stachowiak, "Biomass Productivity and Phytoremidiation Potential of Salix alba and Salix viminalis,” Biomass \& Bioenergy, Vol. 34, No. 9, 2010, pp. 1410-1418. doi:10.1016/j.biombioe.2010.04.012

[6] M. T. Kelly and J. P. Curry, "The Influence of Phenolic
Compounds on the Suitability of three Salix Species as Hosts for the Willow Beetle Phratora vulgatissima," Entomologia Experimentalis et Applicata, Vol. 61, No. 1, 1991, pp. 25-32. doi:10.1111/j.1570-7458.1991.tb02392.x

[7] C. Björkman, S. Höglund, K. Eklund and S. Larsson, "Effects of Leaf Beetle Damage on Stem Wood Production in Coppicing Willow," Agriculture and Forest Entomology, Vol. 2, No. 2, 2000, pp. 131-139. doi:10.1046/j.1461-9563.2000.00058.x

[8] C. Björkman, R. Bommarco, K. Eklund and S. Höglund, "Harvesting Disrupts Biological Control of Herbivores in a short-Rotation Coppice System," Ecological Applications, Vol. 14, No. 6, 2004, pp. 1624-1633. doi:10.1890/03-5341

[9] P. Dalin, T. Demoly, M. F. Kabir and C. Björkman, "Global Land-Use Change and the Importance of Zoophytophagous Bugs in Biological Control: Coppicing Willows as a Timely Example,” Biological Control, Vol. 59, No. 1, 2011, pp. 6-12. doi:10.1016/j.biocontrol.2011.01.010

[10] M. Stolarski, S. Szczukowski, J. Tworkowski and A, Klasa, "Productivity of Seven Clones of Willow Coppice in Annual and Quadrennial Cutting Cycles,” Biomass and Bioenergy, Vol. 32, No. 12, 2008, pp. 1227-1234. doi:10.1016/j.biombioe.2008.02.023

[11] D. A. Kendall, T. Hunter, G. M. Arnold, J. Liggitt, T. Morris and C. W. Wiltshire, "Susceptibility of Willow Clones (Salix spp.) to Herbivory by Phyllodecta vulgatessima (L.) and Galerucella lineola (Fab.) (Coleoptera, Chrysomelidae)," Annals of Applied Biolology, Vol. 129, No. 3, 1996, pp. 379-390. doi:10.1111/j.1744-7348.1996.tb05762.x

[12] A. Lehrman, M. Torp, J. A. Stenberg, R. Julkunen-Tiitto and C. Björkman, "Estimating Direct Resistance in Willows against a Major Insect Pest (Phratora vulgatissima) Comparing Life History Traits,” Entomologia Experimentalis et Applicata, Vol. 144, No. 1, 2012, pp. 93-100. doi:10.1111/j.1570-7458.2012.01244.x

[13] C. Glynn, A. C. Rönnberg-Wästljung, R. Julkunen-Tiitto and M. Weih, ”Willow Genotype, but Not Drought Treatment, Affects Foliar Phenolic Concentrations and LeafBeetle Resistance," Entomologia Experimentalis et Applicata, Vol. 113, No. 1, 2004, pp. 1-14. doi:10.1111/j.0013-8703.2004.00199.x

[14] A. C. Rönnberg-Wästljung, I. Åhman, C. Glynn and O. Widenfalk, "Quantitative Trait Loci for Resistance to Herbivores in Willow: Field Experiments with Varying Soils and Climates," Entomologia Experimaentalis et Applicata, Vol. 118, No. 2, 2006, pp. 163-174. doi:10.1111/j.1570-7458.2006.00371.x

[15] S. Larsson, C. Björkman and R. Gref, "Responses of Neodiprion sertifer (Hym., Diprionidae) Larvae to Variation in Needle Resin Acid Concentration in Scots pine," Oecologia, Vol. 70, No. 1, 1986, pp. 77-84. doi:10.1007/BF00377113

[16] J. I. Glendinning, S. Domdom and E. Long, "Selective Adaptation to Noxious Foods by a Herbivorous Insect," Journal of Experimental Biology, Vol. 204, Pt. 19, 2001, pp. 3355-3367.

[17] D. R. Coyle, K. E. Clark, K. F. Raffa and S. N. Johnson, 
"Prior Host Feeding Experience Influences Ovipositional but Not Feeding Preference in a Polyphagous Insect Herbivore,” Entomologia Experimentalis et Applicata, Vol. 138, No. 2, 2011, pp. 137-145. doi:10.1111/j.1570-7458.2010.01083.x

[18] M. Rowell-Rahier, "The Food Plant Preference of Phratora vitellinae (Coleoptera, Chrysomelinae). B. A Laboratory Comparison of Geographically Isolated Populations and Experiments on Conditioning," Oecologia, Vol. 64, No. 3, 1984, pp. 375-380. doi:10.1007/BF00379136

[19] J. Tahvanainen, R. Julkunen-Tiitto and J. Kettunen, "Phenolic Glycosides Govern the Food Selection Pattern of Willow Feeding Leaf Beetles,” Oecologia, Vol. 67, No. 1, 1985, pp. 52-66. doi:10.1007/BF00378451

[20] M. Torp, A. Lehrman, J. Stenberg, R. Julkunen-Tiitto and C. Björkman, "Performance of an Herbivorous Leaf Beetle (Phratora vulgatissima) on Salix F2 Hybrids: The
Importance of Phenolics,” Journal of Chemical Ecology (Accepted).

[21] J. A. Stenberg, A. Lehrman and C. Björkman, "Uncoupling Direct and Indirect Plant Defences: Novel Opportunities for Improving Crop Security in Willow Plantations," Agrculture, Ecosystems \& Environment, Vol. 139, No. 4, 2010, pp. 528-533. doi:10.1016/j.agee.2010.09.013

[22] J. A. Stenberg, A. Lehrman and C. Björkman, "HostPlant Genotype Mediates Supply and Demand of Animal Food in an Omnivorous Insect,” Ecological Entomology, Vol. 36, No. 4, 2011, pp. 442-449. doi:10.1111/j.1365-2311.2011.01285.x

[23] J. A. Stenberg, A. Lehrman and C. Björkman, "Plant Defence: Feeding Your Bodyguards Can Be CounterProductive,” Basic and Applied Ecology, Vol. 12, No. 7, 2011, pp. 629-633. doi:10.1016/j.baae.2011.08.007 